\title{
Study on Judicial Judgment Criteria Concerning Modification to Employment Contract
}

\author{
Pan Feng ${ }^{1, a,{ }^{*}}$, Xie Weiwei ${ }^{1, b}$ \\ ${ }^{1}$ School of Law, Xiamen University, Xiamen, 361005, P.R. China \\ a xmupanfeng@vip.163.com, b 360532320@qq.com \\ ${ }^{*}$ corresponding author
}

Keywords: Employment Contract; Modification; Judicial Adjudication

\begin{abstract}
This Paper, having a study on the status quo of judgment for dispute heard before Chinese courts in respect to the contract modification, finds that courts throughout the country have set up their own judgment criteria, which are not unified. This Paper believes that the establishment of judgment criteria to measure legality and rationality of modification to employment contract is the key to disposing dispute arising from such modification and balancing both parties' interest. In order to examine the legality of modification to employment contract, it is necessary to determine by means of explaining content specified in a employment contract the scope of modification by an employer to employment contract. And in order to examine the rationality of modification to employment contract, it is necessary to begin with judging the legitimacy of the cause to modify a employment contract, which may be analyzed, based on the operating data provided by the employer and the follow-up acts taken by it for such modification.
\end{abstract}

\section{Introduction}

Article 17 of the Labor Law of PRC has established a principle of modification to employment contract, that is to say, "to follow the principles of equality, voluntariness and unanimity through consultation, and shall not run counter to the stipulations of laws, administrative rules and regulations." - the principle that has mainly raised requirements for the desirable contents of modification to employment contract: "equality, voluntariness and unanimity through consultation." Moreover, Article 35 of the Employment contract Law of PRC has raised a requirement for "in written form" based on the principle established in the Labor Law of PRC, the requirement that only recognizes the desirable modifications may be reflected in written form, and does not recognize such modifications may be reflected otherwise, i.e. excluding other forms of modifications. At present, with descending economy, Chinese corporations, to go through a difficult period, have in most cases lowed their costs in manner of laying off their employees or modifying the employment contracts between them and their employees, yet procedures to lay off employees are very complicated and cost high. In such case, it has become the means those corporations have frequently used to modify the employment contract, a move that can be more capable of playing an important role, that is, "modification to law contract is for the perfection and development of the rights and obligations stipulated in the employment contract, and the important means to ensure fully performing and smoothly realizing of the employment contract." 1 With the frequent modification to employment contract, the number of disputes arising from the modification is on the increase. The resolution of disputes arising from the modification affects not only the interests of the employee and employer, also the normal operation of a corporation and even good operation of the economic order.

Concerns of this Paper are about the status quo of Chinese courts' examination criteria for modification to employment contract, based on the discussion of judicial judgment criteria, to have a rough idea of the current examination criteria for modification to employment contract. Thereafter, this Paper rethinks the current examination criteria for modification to employment contract used by Chinese courts, making suggestions, aimed at problems in practice, on perfection of the judicial judgment criteria. 


\section{Status quo of judicial judgment in respect to modification to employment contract}

With the help of China Judgements Online , this Paper has searched 905 court verdicts in total made during the term "from January 1, 2013 to December 31, 2016" with keywords "Article 35 of the Labor Law of PRC" and "Article 40 of the Employment contract Law", and the limited cause of action "employment contract dispute" of which the keyword is "modification". After cases repetitive and irrelevant to the study herein are excluded, there remain 255 court verdicts finally.

\subsection{Basic information of sample cases}

From contents of modification to labor law, dispute cases between the employer and labor arising out of the change in posts account for the largest proportion, those out of changes in workplaces account for the second, and those out of labor compensation count for the third. In all cases arising out of changes in posts, there are a certain percentage of the job changes, together with changes in labor remuneration, ranks, workplaces, contract subjects and otherwise. Which states that modification to employment contract law is not really a single change in content of conctract, but often there are two or even more than two changes in contract contents.

From the bases of modification to labor law, they are mainly divided into four categories: (1) modification to labor law conducted unilaterally, as for which no cases concerning modification to labor law achieved through searching have been found instituted by employees, hence "modification to labor law conducted unilaterally" only refers to unilateral modification conducted by an employer; (2) agreed modification to labor law, as for which the employer and employee have made and entered into terms permitting modification to employment contract under certain conditions, such terms that are mainly specified in employment contracts and/or rules and regulations of a corporation, with cases based on "stipulations in a contract" to be divided into two categories: one summary and agreeable, granting an employer greater authority to adjust a contract with scarcely any limited conditions; the other attached with procedures, making clear that an employer may modify certain and certain a items of a employment contract, with some procedural requirements, such as consensus and announcement; (3) statutory modification to labor law in which there are maximum cases modified on the basis of "objective conditions changed much", thus it can be seen that such basis is used more frequently when an employer modifies a employment contract; and (4) modification to labor law agreed on by both parties; and from cases got through this research, those concerning modification to contract on the basis of "consensus" are least among the four categories.

From legitimacy of modification to labor law, in all of the sample cases, there are modifications of 124 cases are identified breaking the law by the court, 131 lawful. The former is 7 fewer than the latter, with proportion higher of $2 \%$. All of which state that from quantity proportion of the illegally modified cases no obvious tendencies and broad and strict identification criteria can be seen when a court affirms a case concerning modification to labor law.

\subsection{Factors considered when Chinese courts examine cases involved with modification to labor law}

\subsubsection{Consideration factors in legality examination}

With regard to statutory modification, concerns about examination in judicial adjudication will be to discuss whether or not there is modification is desirable or in written form. As per literal requirements in Article 35 of the Employment contract Law of PRC, first, an employer modifies a employment contract, the court shall first examine whether or not both parties have negotiated. The court will investigate the necessity for negation prior to examining whether or not there is consensus. Second, if the examination has been made in writing or not. With the application of the principle of actual performance to modification to labor law recognized under Article 11 of the Judicial Interpretation (IV), when both parties fail to provide modified employment contract in 
writing, the court will examine whether the contract has been performed more than one month, during which the employee has not had any objection to such modification.

\subsubsection{Consideration factors in rationality examination}

In the process of rationality examination, a court adjudges mainly on the basis of consideration factors as follows:

\subsubsection{Whether the modification is based on requirements for production and management}

It is an investigation into why an employer starts modification whether the same is based on requirements for production and management. Generally speaking, a court's judgment affirms the modifications based on requirements for production and management. In the sample cases, circumstances based on requirements for production and management include the reorganizing and integrating of internal resources to avoid rigid employment, cross exercise together with employees of other employers, resolving of management problems, and revocation of posts or departments. And circumstances unnecessary for production and operation include the forcing of employees to resign, and there being no employees unqualified for certain posts. And in some sample cases, a court carries out a loose necessary examination based on production and operation, affirming simply circumstances are necessary for production and operation, and even part of cases have been affirmed by the court meeting conditions under the circumstance that the employer has not provided evidence that such cases are based on necessary production and operation.

\subsubsection{Whether the labor remuneration has reduced}

Posts may be divided into two categories - transferring post without adjusting salaries and transferring post with adjusting salaries - in accordance with whether or not labor remuneration has changed, among which the proportion is larger of cases regarding transferring post with adjusting salaries. And in general, a court regards the transferring post without adjusting salaries as a key factor to affirm the rationality of transferring post. And some courts hold that transferring post does not means adjusting salaries can be conducted, for which the employer may otherwise agree with the employee with respect to adjusting salaries. However, in some individual cases, the court has recognized the rationality of transferring post with adjusting salaries: in one case, the court has rejected the request of the employee that salaries be paid as per his original post given that both parties have agreed on the transferring post; on the other case, the court has affirmed that the adjusting salaries are reasonable given that such act is by and large in keeping with the principle of equal pay for equal work.

\subsubsection{Whether the modification results in positions and ranks down}

Where a employee is not an ordinary staff member but an officer at a certain level, a court may regard whether there is lowered rank as a factor to affirm reasonable the transferring posts and altering workplace. Generally speaking, a court holds that a employee's rank of post not be lowered in case of transferring posts and altering workplace. But in exceptional cases, a court will permit changing the positions and ranks in case of transferring posts, including the employee not being unqualified for the management or the management post being revoked.

\subsubsection{Relevance of job nature before and after modification}

Relevance of job nature requires that there will be some relevance to the original post after post changes. And relevance of job nature includes two consideration factors: that of job content and of job strength. In the sample cases, post of management technology has transferred to boiler man, technological management to warehouseman, so the court holds that in both cases job content has changed greatly, and that the job content has nothing to do with the employee's professional 
skill, hence an unreasonable transferring post. And job strength is mainly reflected in working hours. And in the sample cases, although the job content is the same, the working hours have been extended drastically, hence in the view of the court that the job strength has been enhanced obviously.

\subsubsection{The impact on the lives of laborers}

Examining the rationality of the changes in the workplace, the court will pay special attention to the investigation of whether or not the effects of such changes are substantial on the employee's life. Where the location changes are within the scope for the employee to go there and back in one day, the court will examine changes in employee's working hours, convenience of traffic and transportation burden. Unreasonable changes in places such as unreasonably extended commuter time, no convenient traffic and much more transportation for employee to burden. In the event of the changes in places across provinces and cities, then the employee's acceptance of the changes means to completely living in another place, the court will examine whether the employee's family and his/her duty of support are considered when the place is changed. Provided that change in the place hinders employees to perform their duty, having a strong impact on their families, it is unreasonable.

\section{Existing questions about Chinese court's judgment criteria}

Chinese court's judgment criteria concerning the legitimacy and rationality of modification to employment contract can roughly be reduced to: (1) determining whether they fall into a statutory modification or negotiated one; (2) whether modification to labor law is desirable; (3) whether they are based on requirements for production and operation; (4) whether there are any adverse changes in labor remuneration; (5) effect of relevance to posts and ranks, and to job nature on the employee, and his/her employer's assistance obligations, etc.; and (6) whether there is any violation of laws, administrative regulations and state policies as well as public order and good custom. This Paper finds the problems as follows, via study on the status quo of judicial adjudication:

First, not all the judicial adjudications concerning modification to labor law have been examined in strictly accordance with the aforementioned criteria, some adjudication made only by one the criteria, some made by several of the criteria, so that there are results varying with judgment criteria applied by a court in similar cases.

Second, there are no specific approaches to resolving dispute, mainly consideration factors of rationality; because there is no primary and secondary difference between such factors, and no specific approaches to resolving the dispute between the two consideration factors, circumstances arise that one remains unchanged and that the other become extremely adverse.

Third, by the same judgment criteria, a court examines different emphases, for example, whether there are desirable judgments, whether the court will first examine contracts modified in writing, and whether the modification is verbal and its actual performance for more than one month after both parties fails to provide contracts modified in writing. Part of the judicial adjudication, in terms of examining whether there is a verbal modification and the actual performance for more than one month, focuses on examining the actual performance time, rather than on whether the two parties reach a consensus on the modification orally. But in practice, there are a lot of employees lack such legal consciousness and knowledge, without realizing that the two parties have formulated modification to contract. So it may put the cart before the horse that the court deems "actual performance for one month" as the examination key.

Last, parts of contents are not so clear of the criteria. For instance, on the basis of requirements for production and operation, some courts hold that the modification cause is based on such 
requirements, constituting a proper modification cause; while some courts think a proper modification cause must be based on the production and operation required, that is to say, modification is not a dispensable but a must-do move so far as the production and operation is concerned. And for another instance, when effects have been examined of the modification to a workplace on a employee, how far the distance can cause substantial impact on the employee's life, which can be judged as per commuter time or transportation cost, or the convenience of the traffic.

\section{Perfection of Chinese judicial judgment criteria for modification to labor law}

\subsection{Establishment of principle of benefit balance}

In labor law relations, one of the biggest contradictions is that the employer and the employee have such individual interest requirements that the two parties, in the pursuit of self-interest, will inevitably damage the interests of the other party. Therefore, the Labor Law of PRC shall make clear and definite the respective rights and obligations of the employer and the employee, and balance the relationship between both parties, the fundamental task of the Law. At the same time, given that the employee in the relationship is in a weak position, legislation shall be inclined to protect him/her. However, that mean not giving up the interests of the employer but seeking the boundary of benefit balance to make the corporation develop and grow and to protect the interests of the employee simultaneously.

As to problems and issues on modification to labor law, requirements in written form are for reasons of inclined protection of the employee, limiting that the employer arbitrarily modifies the employment contract with his/her strong position. But the excessive emphases on the written form not only hamper the employer's normal exercise of decision-making power to employ the employee also harm interest of the employee. In favorable changes, for example, employee often cannot provide written evidence of modification to labor law. The ultimate goal of legislation of labor relations is to develop healthy and stable labor relations, so when regulating act of modification to labor law, one should take into account both interest requirements the employer and those of the employee.

\subsection{Establishment of examination criteria for validity}

Where the content of modification falls outside of a employment contract, the modification must be consent by the employee; where the content of modification falls into the employment contract, the modification isn't to labor law but the performance of the employment contract. Therefore, for broad terms, the court can explain these terms in an active way in the process of examination, determining, in accordance with the actual post and workplace of the employee, the post and workplace as agreed in the employment contract made and entered into by and between both parties. When the actual post and workplace cannot be confirmed, the court may use general interpretation rules concerning the Contract Law of PRC - in the event of any dispute arising from and in connection to vague or ambiguous terms, the interpretation should be adopted against the party formulating such terms. As for anything not covered clearly in the employment contract, the court may refer to the method of "implied terms", that is, it is the court that will resolve the dispute in the light of laws and regulations as well as public orders and good customs. Where the "Theory of Employment contract" is applied, the rigid examination mode can be broken of "consensus+written form”, a move that not only values the autonomy in management of the employer, but the employer's and the employee's interests, too.

Agreed terms are different from broad terms, the former not agreement on concrete content of a employment contract, but on being under what circumstances does the employer have the right to adjust a certain content of the contract unilaterally. Hence, the effectiveness and validness of the agreed terms shall be exanimated otherwise. The practice of fully affirming and not imposing any 
limit on the effectiveness and validness of the agreed terms is negligence towards that these terms in nature are standard terms. In concluding a employment contract, the employee, like the employer, is unable to foresee any change in the future, and he/she transfer his/her right to modify unilaterally the contract to the employer completely, excluding and depriving decision-making power to modify the employment contract through his/her consultation with the employer. Moreover, completely denying the effectiveness and validity of the agreed terms means negligence towards that the agreed modification terms are to represent the business management right the employer adjusts in time to deal with the market changes, and violates the principle of "autonomy of will” under private law. Therefore, the examination of these agreed terms should on the premise of affirmation of their effectiveness and validness focus on examination of rationality of modification to them; inconvenience to, and burden on, the employer's families caused by the modification; and whether or not there are any improper motivation and purpose in the modification.

The cause behind the modification behavior may be various, such as corporation's business needs, punishment of employees, and even forced leaving office of employees; therefore it is necessary to make a thorough inquiry into whether modification cause is justified. Determination of the cause may be based on evidence the employer submits, such as corporation's business needs; where the business data and related information the employer provides can prove that the case exists, then the cause is legitimate. If the employer fails to provide sufficient evidence, the court can judge whether the modification has any relation to business operation, on the basis of other details, judgment criteria and follow-up actions the employer takes related to the modification. If the modification is based on the unilateral modification necessary for business operation and on the objective conditions that change much, then it is necessary not just to determine the association with business operation, also to strictly examine whether the modification is required for the business, that is to say, the modification is a must-take means to ensure the operation of enterprises.

\section{Conclusions}

Modification to the labor law is a means the employer uses to integrate human resources, and maintain the normal operation of a corporation. It becomes a problem how to with the judicial adjudication settle satisfactorily a dispute arising out of and in connection to the modification to labor law and at the same time balance the employer's and the employee's interests. Too loose examination will make the employer have an opportunity to abuse rights, optionally modifying the employment contract so that the interests of the employee are damaged; too harsh examination will interfere with satisfaction of necessaries for normal production and operation of the employer, harmful to economic development. As for how to seek for a balance point in contradiction, the key is to establish in the judicial adjudication appropriate judicial examination criteria. This Paper argues that it is the key to handling the dispute arising from modification to labor law and balancing both parties' interests to set up the judgment criteria to measure legitimacy and rationality of modification to labor law. The examination of the legitimacy of modification to labor law should be based on the interpretation to determine the scope of the modification to the employment contract that the employer makes unilaterally. In the course of rationality examination, it is in the first place to examine the legitimacy of the cause of modification to labor law, which can be based on the business data the employer provides and the follow-up acts the employer takes concerning such modification. In specific cases, it can be adjudged on the basis of the effects it causes to the labor remuneration, family life, post level and job nature of the employer.

\section{Acknowledgements}

Supported by “the Fundamental Research Funds for the Central Universities”,T2013221003. 


\section{References}

[1] Dong Baohua. (2015). Contention and Reflection on Employment Contract Law. Shanghai: Shanghai People’s Publishing House.

[2] Hou LingLing. (2013) . On Job Transfer in Enterprise. Legal Science, 5, 106-115.

[3] Liu Songzhen. (2011) . A preliminary study on the transfer legal issues. Journal of Changchun University, 5, 64-66.

[4] Lin Geng-Schenq. (2013) . Judicial Interference on the Transfer Rights of Employers.Court Case Times, 20, 5-15.

[5] Sun Guoping. (2016) .Judicial Interference on Employers'Right to Change Terms and Conditions of Labor Contracts. Journal of Comparative Law, 1, 28-51.

[6] Wang Quanxing. (2007). Interpretation of Labor Contract Law. Beijing: China Legal Publishing House.

[7] Wang Linqing. (2011). Arbitration Criteria and Norms for Labor Dispute. Beijing: People's Publishing House.

[8] Wang Quanxing. (2008). Labor Law. Beijing: Law Press. 